\title{
Synthesis of Gold Nanoparticles Using $p$-Aminobenzoic Acid and p-Aminosalicylic Acid as Reducing Agent
}

\author{
Abdul Aji, Eko Sri Kunarti*, and Sri Juari Santosa \\ Department of Chemistry, Faculty of Mathematics and Natural Sciences, Universitas Gadjah Mada, \\ Sekip Utara, Yogyakarta 55281, Indonesia
}

* Corresponding author:

email:eko_kunarti@ugm.ac.id

Received: July 23, 2017

Accepted: October 12, 2018

DOI: $10.22146 / \mathrm{ijc} .26839$

\begin{abstract}
Synthesis of gold nanoparticles (AuNPs) by reduction of $\mathrm{HAuCl}_{4}$ with $\mathrm{p}$ aminobenzoic acid and p-aminosalicylic acid as a reducing agent was investigated. This work was conducted in order to determine the optimum condition of AuNPs synthesis and examine the effect of the hydroxyl group in p-aminosalicylic acid towards the size, shape, and stability of the synthesized gold nanoparticles (AuNPs). The optimum condition of the gold nanoparticles synthesis was determined by UV/Vis spectrophotometer, the shape and size of gold nanoparticles were measured by Transmission Electron Microscope (TEM). The synthesis process was started by reacting $\mathrm{HAuCl}_{4}$ and the reducing agents in an aqueous solution at $86^{\circ} \mathrm{C}$. The initial gold concentration, reducing agents concentration and $\mathrm{pH}$ were varied in order to obtain the optimum condition. In the optimum condition, the results showed that $\mathrm{p}$-aminosalicylic acid containing both hydroxyl and amino groups performed higher reduction ability compared to p-aminobenzoic acid that only containing an amino group. Reducing agents which have a hydroxyl group ( $\mathrm{p}$-aminosalicylic acid) could produce AuNPs with a smaller concentration of $\mathrm{HAuCl}_{4}$ than $\mathrm{p}$-aminobenzoic acid. Gold nanoparticles that were synthesized with $\mathrm{p}$-aminosalicylic acid were more stable and had a smaller particle size compared to its counterpart that is synthesized with p-aminobenzoic acid.
\end{abstract}

Keywords: gold nanoparticles; p-aminosalicylic acid; p-aminobenzoic acid

\section{- INTRODUCTION}

Gold has the lowest electrochemical potential among metals. This means that gold in any cationic form will accept electrons from any reducing agent to form metallic gold. Pure gold has electrical properties and high thermal conductivity compared to other metals [1]. Generally, gold has been used in various fields such as jewelry[2]. It also used in water purifier system because of its antimicrobial activity [3].

Gold with the bulk size has a small surface area and it reduces its reactivity. To solve this problem, gold can be synthesized in nanoparticle size. The size of gold nanoparticles can increase the effectiveness of its optic performance, due to the larger surface area [4]. Gold nanoparticles are widely studied because of its extraordinary properties that might have a strong impact on different science and technology fields. The interest in these fascinating nanostructures covers a wide range of specific areas, as heterogeneous catalysis, optics, sensitive analysis and medicine [5].

The gold nanoparticle can be formed by physical or chemical methods. Some chemical methods which used to form gold nanoparticle are a chemical reduction [6-8], electrochemical [9], photochemical and sonochemical [10], microwave-assisted synthesis [11] and recently, using of green chemistry [12]. Chemical reduction technique is also known as self-assembly process, which is done by mixing the desired precursor particles with a reducing agent and stabilizer in the form of inorganic chemicals to form nanoparticles. Chemical reduction is a popular method due to its easiness, relatively low-cost, and production possibility on a large scale [13].

In the synthesis of gold nanoparticles (AuNPs), using coordination agents that stabilize and control the 
morphological evolution of the gold nanostructures in solution or suspension are useful tools [14]. Stabilizer used to protect the particles from aggregation and reduce the collision possibility between particles of gold, in order to make AuNPs become stable [15]. The formation of stable AuNPs are indicated by the colloid formation with red or purple color and has a strong adsorption of visible light at the wavelengths between 520-550 nm [16]. Previous studies have been conducted by using different chemicals as reducing agent and stabilizer, such as chitosan, thiocholine, and glucose [17] but it becomes less efficient. Therefore, alternative chemicals which can act as good reducing agent and also as stabilizer are needed. Aziz et al. [18] have carried out the synthesis of AuNPs using pamoic acid as a reducing agent as well as a stabilizer. The reduction process occurs by the presence of hydroxyl group $(\mathrm{OH})$ that can reduce $\mathrm{Au}^{3+}$ to $\mathrm{Au}^{0}$ and the presence of the carboxylic group (-COOH) facilitate electrostatic interactions with $\mathrm{Au}^{3+}$ ions in solution. This interaction prevents the aggregation of $\mathrm{Au}^{3+}$ ions, and as a result, precipitation could be avoided.

In this study, we use $p$-aminobenzoic acid and $p$ aminosalicylic acid as reducing and stabilizing agent, because of amino group and amino with hydroxyl group contained in $p$-aminobenzoic acid and $p$-aminosalicylic acid, respectively. Therefore, those reactants are expected to reduce $\mathrm{Au}^{3+}$ into $\mathrm{Au}^{0}$ and stabilize the synthesized gold nanoparticles during the synthesis. Previous studies confirmed that $p$-aminobenzoic acid could be used as a reducing agent in reaction with 2,6-dichloroquinone-4imide [19]. Therefore, this study critically optimized the synthesis condition of gold nanoparticles and verified the effect of hydroxyl group contained on $p$-aminosalicylic acid. The examined parameters were the size, shape, and stability of the particles.

\section{- EXPERIMENTAL SECTION}

\section{Materials}

The materials that used in this research were gold(III) chloride acid solution ( $\left.\mathrm{HAuCl}_{4} 1000 \mathrm{ppm}\right), p$ aminobenzoic acid $\left(\mathrm{C}_{7} \mathrm{H}_{7} \mathrm{NO}_{2}\right.$, Merck), $p$-aminosalicylic acid $\left(\mathrm{C}_{7} \mathrm{H}_{7} \mathrm{NO}_{3}\right.$, Merck), sodium hydroxide $(\mathrm{NaOH}$, Merck), and hydrochloric acid (HCl, Merck).

\section{Instrumentation}

The instruments used were laboratory glassware, hot plate with stirrer, thermometer, $\mathrm{pH}$-meter (HI 98103 by Hanna Instrument), water-bath, analytical balance, UV-Vis spectra of the synthesized materials were measured with a Shimadzu UV-1700 PharmaSpec instrument, Transmission Electron Microscope imaging were recorded with a TEM JEOL JEM 1400 with a 120 $\mathrm{kV}$ acceleration voltage, $\mathrm{X}$-ray diffraction pattern is obtained on Rigaku Miniflex600 using $\mathrm{Cu}$ ka radiation.

\section{Procedure}

\section{Synthesis of gold nanoparticles}

AuNPs were synthesized by reducing $\mathrm{HAuCl}_{4}$ solution with the $p$-aminobenzoic acid and $p$ aminosalicylic acid as reducing agents at $1-14 \mathrm{pH}$ range by adding a solution of $\mathrm{HCl}$ or $\mathrm{NaOH}$. Three $\mathrm{mL}$ of 0.02 $\mathrm{mM}$ reducing agent which has a $\mathrm{pH}$ range from 1 to 14 were put into a test tube and $3 \mathrm{~mL}$ of $100 \mathrm{ppm} \mathrm{HAuCl}_{4}$ solution was added. The mixture was heated in the water-bath at temperature $86^{\circ} \mathrm{C}$ for $60 \mathrm{~min}$. The color of the mixture was changing from colorless (a little bit yellowish) to pink, indicating the gold nanoparticles formation. The UV-Vis spectra of the mixture solution were analyzed using UV/Vis Spectrophotometer at a wavelength of 200-800 $\mathrm{nm}$. The presence of maximum absorption at the wavelength range of $520-550 \mathrm{~nm}$ showed that AuNPs were formed. The optimum $\mathrm{pH}$ was determined by the highest absorbance on UV-Vis spectra.

\section{Optimization of $\mathrm{HAuCl}_{4}$ solution concentration, reducing agent concentration and study of reducing agent sensitivity}

Three milliliter of reducing agent solution with optimum $\mathrm{pH}$ condition was added into $3 \mathrm{~mL}$ of $\mathrm{HAuCl}_{4}$ solution with the varied concentration $(20,40,60,80,90$, $100,110,120,130,140$ and $170 \mathrm{ppm}$ ) and also added into 5 tubes without the addition of $\mathrm{HAuCl}_{4}$ precursor. All solutions were heated at the temperature of $86^{\circ} \mathrm{C}$ on the water-bath for $60 \mathrm{~min}$. The resulting solutions then were analyzed with UV/Vis spectrophotometer at a wavelength of $200-800 \mathrm{~nm}$. The optimum concentration of $\mathrm{HAuCl}_{4}$ was determined by the maximum absorbance 
of the concentration series.

To determine the optimum reducing agent concentration, $3 \mathrm{~mL}$ of reducing agent solution with varied concentration $(10,15,20,25,30,35,40 \mathrm{mM})$ and optimum $\mathrm{pH}$ condition was added into $3 \mathrm{~mL}$ of $\mathrm{HAuCl}_{4}$ solution with optimum concentration. All solutions are heated at the temperature of $86^{\circ} \mathrm{C}$ in a water bath for 60 min. The resulting solutions then were analyzed using UV/Vis spectrophotometer at a wavelength of 200-800 $\mathrm{nm}$. The optimum concentration of reducing agent was determined by the maximum absorbance of the concentration series.

The absorbance of the solution was measured without the addition of $\mathrm{HAuCl}_{4}$ solution as much as 5 repetitions in order to determine the sensitivity of the reducing agent. The averaged absorbance of the blank solution was calculated in order to plot on the graph of $\mathrm{HAuCl}_{4}$ concentration and the maximum absorbance of the non-blank solution. The linear regression equation was calculated and the sensitivity of the reducing agent was determined from its slope. Higher sensitivity was defined by a sharper angle of the slope.

\section{Study of the gold nanoparticles stability}

Three milliliters of reducing agent solution with the optimum condition was added into $3 \mathrm{~mL}$ of $\mathrm{HAuCl}_{4}$ solution with optimum concentration. The solution was heated at temperature of $86^{\circ} \mathrm{C}$ in the water-bath for 60 min and then analyzed with UV/Vis spectrophotometer at a wavelength of $200-800 \mathrm{~nm}$, at the interval of $0-4 \mathrm{~h}$, 1-4 days, 1-5 weeks after the synthesis process. The absorbance change or maximum absorbance wavelength shift was observed during the storage.

\section{Characterization of gold nanoparticles}

Three milliliters of reducing agent solution with the optimum condition was added into $3 \mathrm{~mL}$ of $\mathrm{HAuCl}_{4}$ solution with optimum concentration. The solution was heated at a temperature of $86^{\circ} \mathrm{C}$ in the water bath for 60 min. Furthermore, the colloidal gold nanoparticles that formed were characterized using TEM to determine the shape and size of the nanoparticles.

\section{- RESULTS AND DISCUSSION}

\section{Synthesis of Gold Nanoparticles}

The $\mathrm{pH}$ value is one of the important factors in the synthesis of gold nanoparticles. In this research, $\mathrm{pH}$ was varied from 1 to 14 by adding $\mathrm{NaOH}$ or $\mathrm{HCl}$. For $p$ aminosalicylic acid changed its color from colorless to red in a $\mathrm{pH}$ condition more than 11 . On the other hand, $p$-aminobenzoic acid changed its color from colorless to pink at 13 value of $\mathrm{pH}$ scale. Pink or red color of the solution was caused by the nanoparticle structure with a specific surface plasmon resonance (SPR). At the basic condition, the proton of hydroxyl and carboxylate group on the $p$-aminobenzoic acid and $p$-aminosalicylic acid will be deprotonated and form a negative charge that increases its metal binding activity, creating the gold nanoparticles. A higher $\mathrm{pH}$ resulted in a high-density solution because more reduction occurred which means more gold nanoparticles contained there. The same conclusion also reported by previous studies [20].

Furthermore, the solutions were analyzed by UVVis spectrophotometer at the wavelength range of 300 $800 \mathrm{~nm}$. The formation of gold nanoparticle was indicated by the maximum absorbance which happened in the wavelength range of 520-550 $\mathrm{nm}$ [21]. The result (see Fig. 1) showed that the gold nanoparticles were formed in the basic condition for both $p$-aminobenzoic acid and $p$-aminosalicylic acid reducing agent. The optimum $\mathrm{pH}$ for $p$-aminobenzoic acid and $p$ aminosalicylic acid reducing agent are 13 and 12, respectively. This difference happened because each reducing agent has specific deprotonated form.

One of the factors that influence the synthesis of gold nanoparticle is the concentration of $\mathrm{HAuCl}_{4}$ precursor. The higher concentration of $\mathrm{HAuCl}_{4}$ produced more gold nanoparticle, which could be indicated by the higher absorbance value [22]. The UV/Vis spectrophotometer measurement result (Fig. 2) showed that the higher salt precursor concentration gave higher absorbance for a $p$-aminosalicylic acid reducing agent. However, for a $p$-aminobenzoic acid reducing 

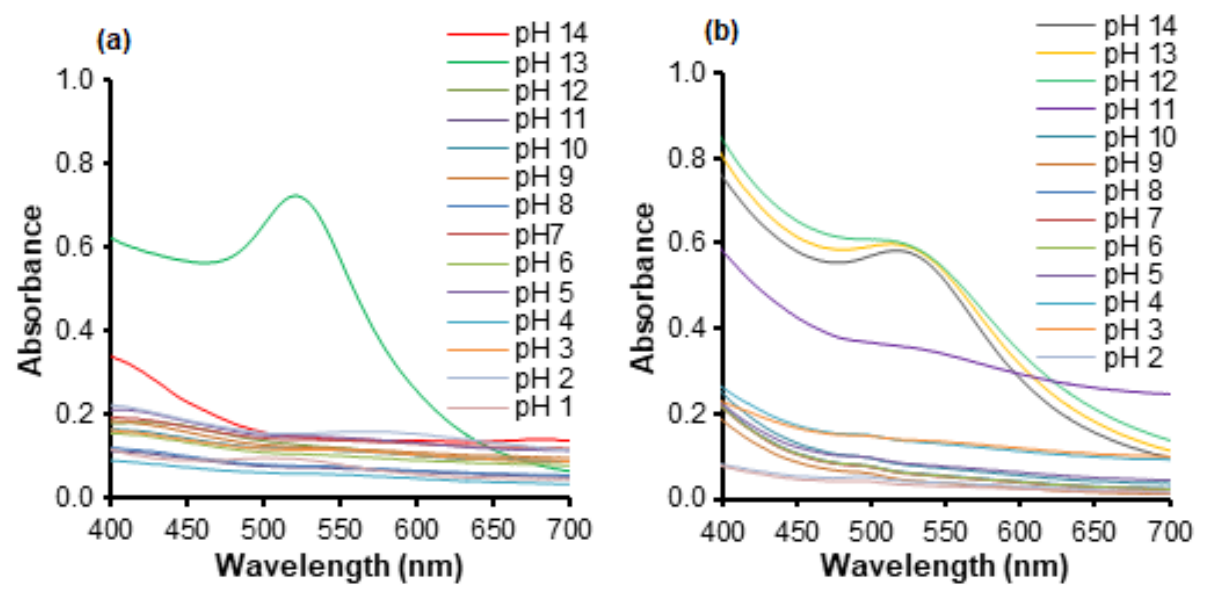

Fig 1. UV/Vis spectra of gold nanoparticle with the precursor of $\mathrm{HAuCl}_{4} 100 \mathrm{ppm}$ and (a) $p$-aminobenzoic acid 20 $\mathrm{mM}$ (b) $p$-aminosalicylic acid reducing agent $20 \mathrm{mM}$ at the $\mathrm{pH}$ range $1-14$
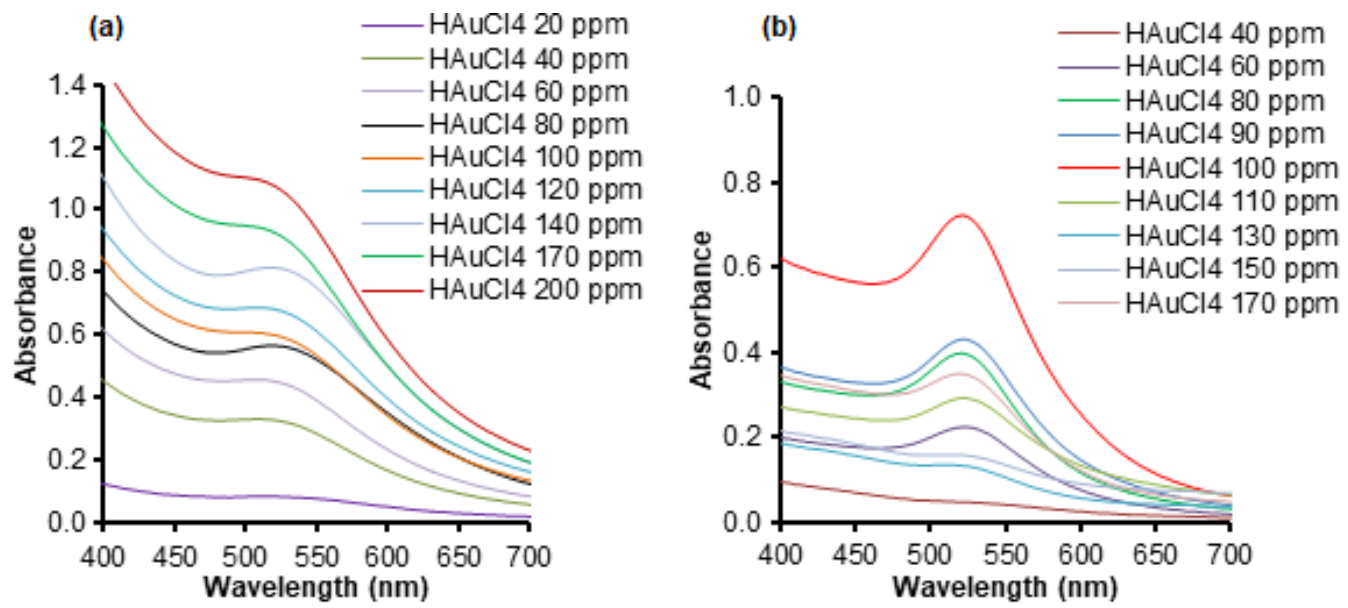

Fig 2. UV/Vis spectra of gold nanoparticle with varied concentration precursor of $\mathrm{HAuCl}_{4}$ with (a) $p$-aminosalicylic acid $20 \mathrm{mM}$ at $\mathrm{pH} 12$ and (b) p-aminobenzoic acid $20 \mathrm{mM}$ at $\mathrm{pH} 13$
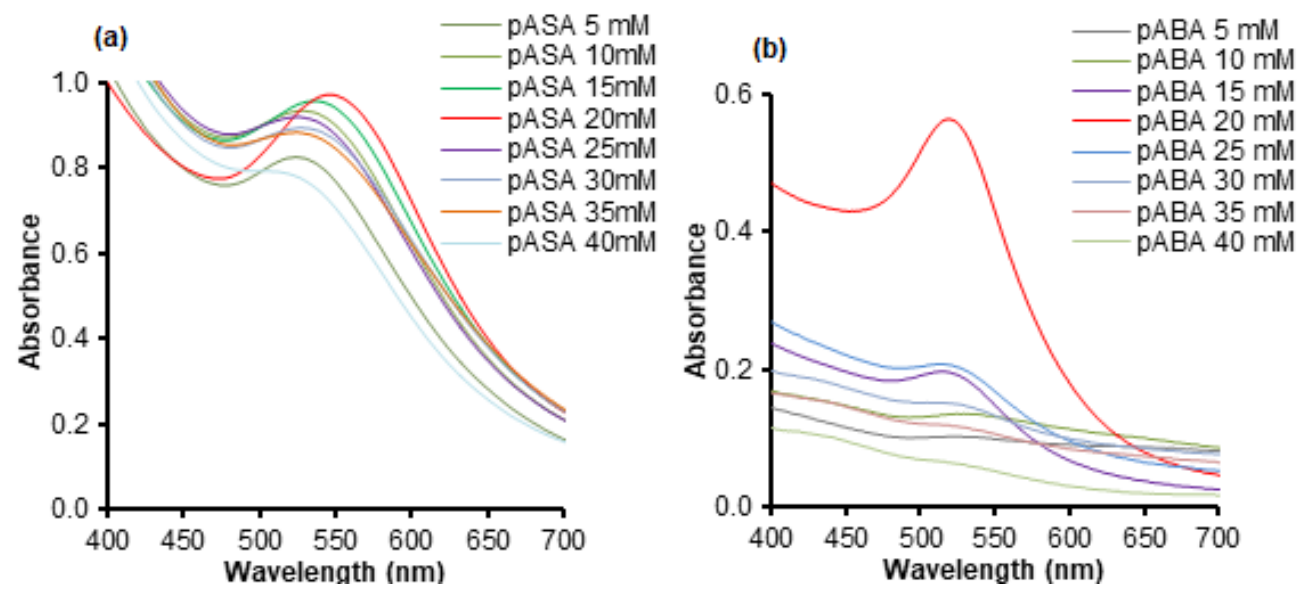

Fig 3. UV/Vis spectra of gold nanoparticle with varied concentration of reducing agent (a) $p$-aminosalicylic acid at $\mathrm{pH}$ 12 and (b) p-aminobenzoic acid at $\mathrm{pH} 13$ 
agent, the highest absorbance showed at a concentration of $\mathrm{HAuCl}_{4} 100 \mathrm{ppm}$. The higher concentration of $\mathrm{HAuCl}_{4}$ decreased the absorbance of a gold nanoparticle. Therefore, the optimum concentration of $\mathrm{HAuCl}_{4}$ for the $p$-aminobenzoic acid reducing agent was obtained at $100 \mathrm{ppm}$.

Another factor that influences the synthesis of gold nanoparticle is the concentration of the reducing agent. The UV/Vis spectra (Fig. 3) showed that the highest reducing agent concentration for both $p$-aminobenzoic acid and the $p$-aminosalicylic acid reducing agent was $20 \mathrm{mM}$. Both spectra showed an equal tendency, where the higher reducing agent concentration gave higher absorbance until the maximum concentration at $20 \mathrm{mM}$.

A reducing agent with the concentration more than $20 \mathrm{mM}$ had a lower UV-Vis absorbance. The graph in Fig. 4 obtained from the maximum absorbance of every precursor concentration and the average of the absorbance from non-precursor solution. This graph used to calculate the linear regression equation which can determine the reducing agent sensitivity. The higher slope value defines a higher sensitivity of the reducing agent.
From the slope data, the AuNPs that synthesized by $p$-aminosalicylic acid had higher slope value (0.0069) than the same material synthesized by $p$-aminobenzoic acid (0.0062). As a result, $p$-aminosalicylic acid had better sensitivity than a $p$-aminobenzoic acid reducing agent. It happened because $p$-aminosalicylic acid contained both hydroxyl group and amino group, while

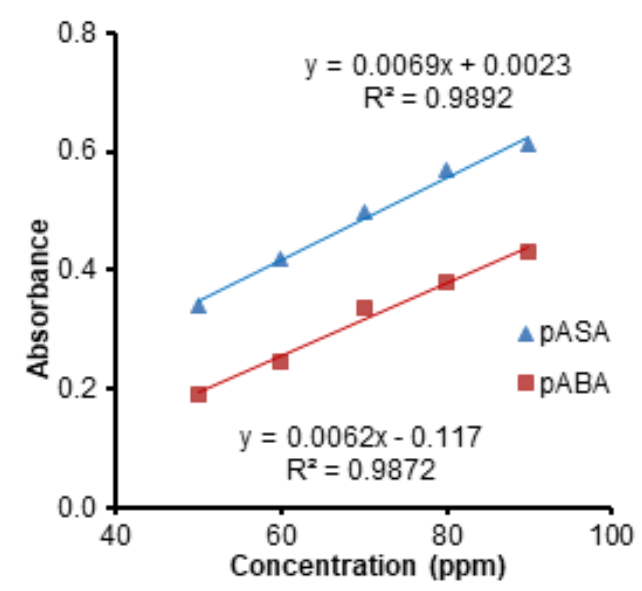

Fig 4. Relation graph of $\mathrm{HAuCl}_{4}$ concentration with gold nanoparticles absorbance which formed by $p$ aminosalicylic acid and $p$-aminobenzoic acid<smiles>Nc1ccc(C(=O)[O-])cc1</smiles>

p-aminobenzoic acid<smiles>CC(C)[GeH2]c1ccc([N+](=O)[O-])cc1C(=O)[O-]</smiles>

Fig 5. Possible mechanism of gold nanoparticles formation by $p$-aminobenzoic acid 
<smiles>[CH+]C=C[CH+]C</smiles>

p-aminosalicylic acid

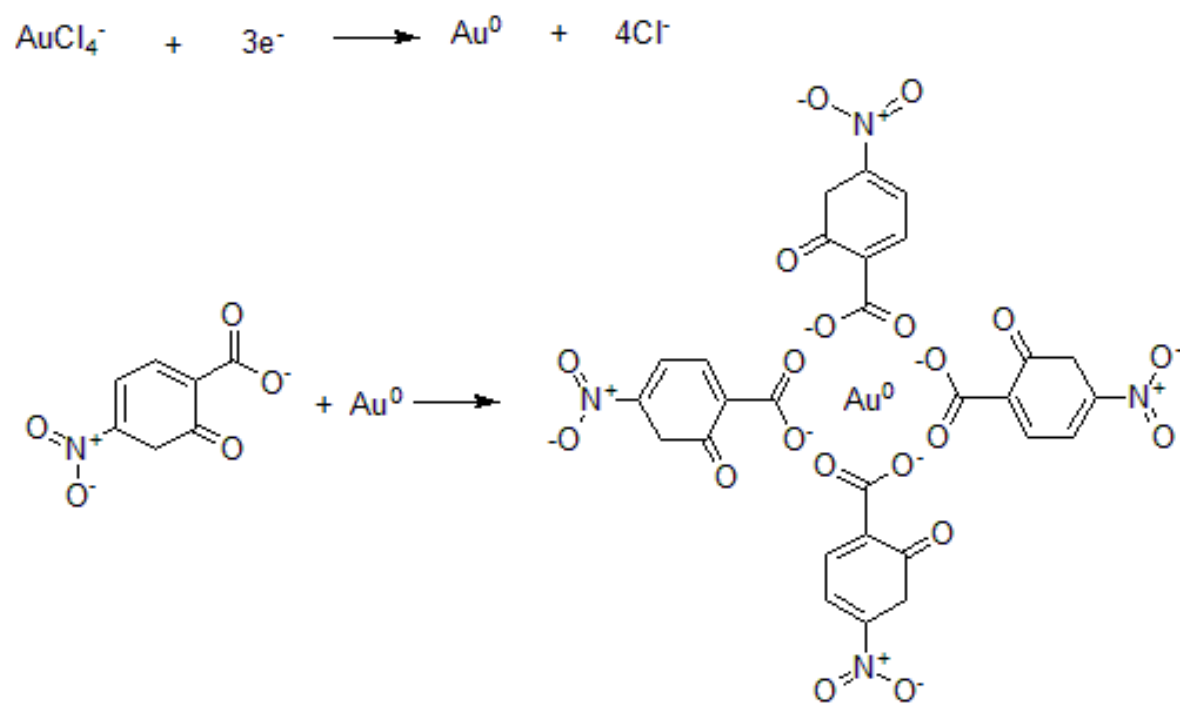

Fig 6. Possible mechanism of gold nanoparticles formation by $p$-aminosalicylic acid (pASA)

its counterpart only had an amino group. Hydroxyl group and an amino group in reducing agent acted as the lone pair electron donor for gold ion, especially $\mathrm{Au}^{3+}$. The presence of hydroxyl group in reducing agent can give more lone pair electron to the gold ion, so it can react more easily with gold ion [23]. Therefore, apart from the amino group, hydroxyl group in $p$-aminosalicylic acid could also enhance the reduction ability of this reducing agent. As a result, $p$-aminosalicylic acid could reduce $\mathrm{Au}^{3+}$ faster than $p$-aminosalicylic acid. The mechanism of gold nanoparticles formation from the reduction of $\mathrm{Au}^{3+}$ with $p$-aminobenzoic acid and $p$-aminosalicylic acid is introduced in Fig. 5 and 6.

\section{Study of the Gold Nanoparticles Stability}

The stability of gold nanoparticles can be described by observing the intensity change of absorbance peak. The shift of maximum absorbance wavelength and the change of absorbance value indicated that the resulted gold nanoparticles are not stable. After the observation for several weeks, all synthesized gold nanoparticles did not give a significant decrease of absorbance value (Fig. 7), only 0.031 for a $p$-aminosalicylic acid reducing agent and 0.098 for a $p$-aminobenzoic acid reducing agent after 5 weeks of storage. This data indicated that all gold nanoparticles were stable until the $5^{\text {th }}$ week.

Apart from the absorbance decrease, the stability of gold nanoparticles can also be examined from the maximum wavelength shift. The maximum wavelength shift happened after 5 weeks as far as $2 \mathrm{~nm}$ for $p$ aminosalicylic acid and $6 \mathrm{~nm}$ for $p$-aminobenzoic acid. The longer storage could decrease the gold nanoparticle stability because of the suspension formation by agglomeration. This phenomenon indicated by the increase of the maximum wavelength and the decrease of the absorbance. However, after the peak shift, the maximum wavelength was still located around $525 \mathrm{~nm}$. It proved that the gold nanoparticle had good stability.

The best stability showed by gold nanoparticles with the $\mathrm{HAuCl}_{4}$ precursor concentration of $140 \mathrm{ppm}$ for a $p$-aminosalicylic acid reducing agent and $100 \mathrm{ppm}$ for a $p$-aminobenzoic acid-reducing agent with the concentration of both $p$-aminobenzoic acid and the $p$ aminosalicylic acid reducing agent was $20 \mathrm{mM}$. The gold 


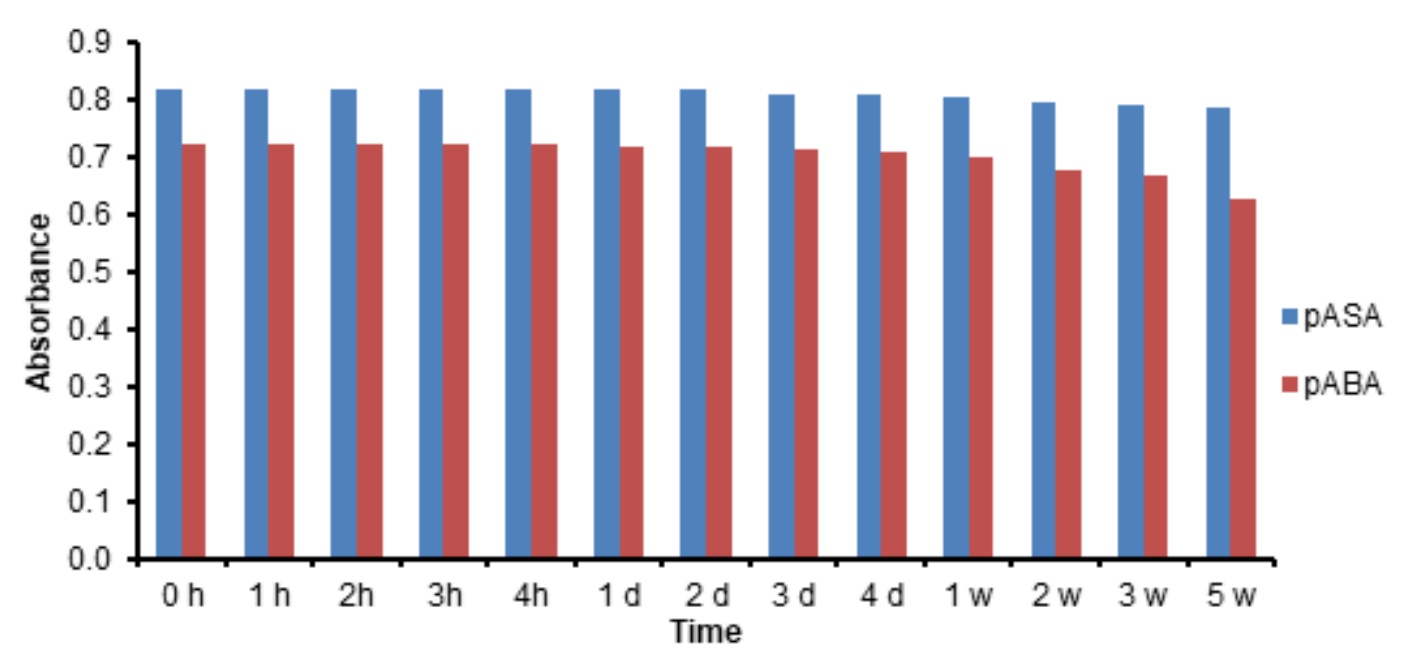

Fig 7. Stability of gold nanoparticles synthesized by $p$-aminosalicylic acid (pASA) at $\mathrm{pH} 12$ and $p$-aminobenzoic acid (pABA) at $\mathrm{pH} 13$ as reducing agent
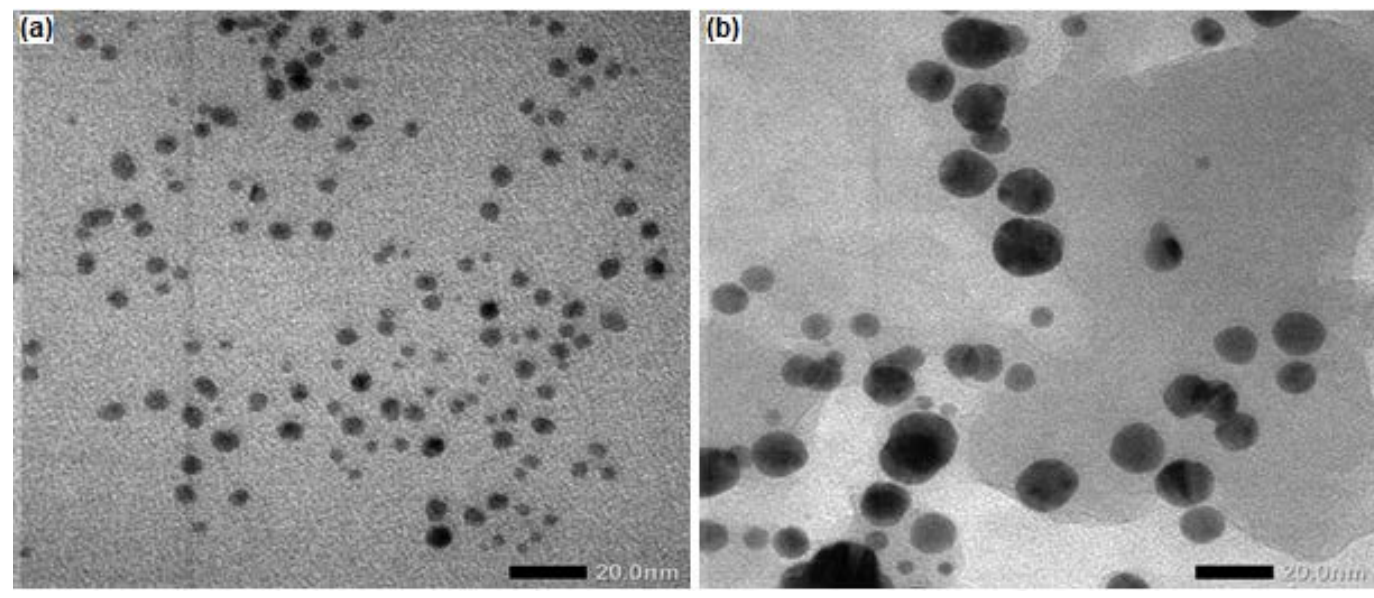

Fig 8. The TEM image of gold nanoparticle synthesized by a reducing agent (a) $p$-aminosalicylic acid at $\mathrm{pH} 12$, the concentration of $\mathrm{HAuCl}_{4} 140 \mathrm{ppm}$ and concentration of reducing agent $20 \mathrm{mM}$ (b) p-aminobenzoic acid at pH 13, the concentration of $\mathrm{HAuCl}_{4} 100 \mathrm{ppm}$ and concentration of reducing agent $20 \mathrm{mM}$

nanoparticles that synthesized with $p$-aminosalicylic acid were more stable compared to the gold nanoparticles synthesized with $p$-aminobenzoic acid. It happened because the $p$-aminosalicylic acid has the highest $\mathrm{pKa}$ value than another reducing agent so it can form a more stable organic molecule anion in the complex form of gold-reducing agent and the aggregation can be inhibited.

\section{Characterization of the Gold Nanoparticles}

The shape and size of gold nanoparticles were measured using TEM. Based on the optimum absorbance condition and their good stability, gold nanoparticles synthesized from $\mathrm{HAuCl}_{4} 140 \mathrm{ppm}$ precursor for $p$ - aminosalicylic acid reducing agent $20 \mathrm{mM}$ at $\mathrm{pH} 12$ and second specimen synthesized from $\mathrm{HAuCl}_{4} 100 \mathrm{ppm}$ precursor for $p$-aminobenzoic acid reducing agent $20 \mathrm{mM}$ at $\mathrm{pH} 13$ were chosen to be measured.

The TEM results showed that both of reducing agent gave same particle shape but different size of gold nanoparticles. The $p$-aminosalicylic acid reducing agent gave round shape and smaller particle size $(7.45 \pm 1.5 \mathrm{~nm})$ than gold nanoparticles synthesized with $p$-aminobenzoic acid (see Fig. 8(a)). For $p$-aminobenzoic acid reducing agent gave round shape and less uniform size (16.05 \pm $7.57 \mathrm{~nm}$ ) of gold nanoparticles (see Fig. 8(b)). The aggregation did not happen with both $p$-aminobenzoic 


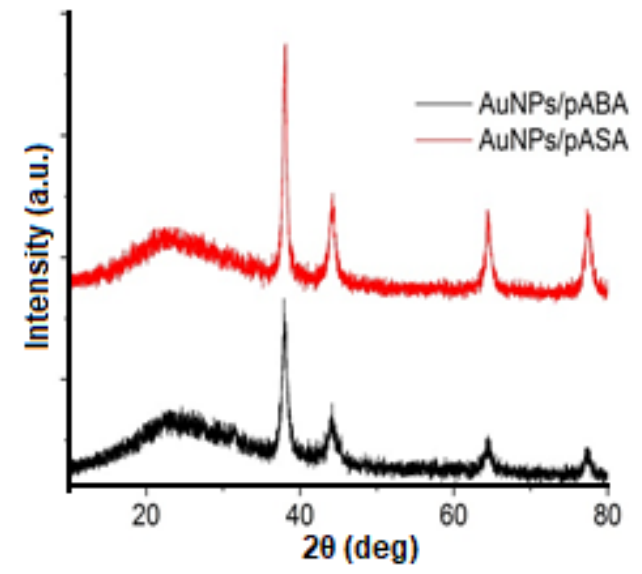

Fig 9. XRD Pattern of gold nanoparticles synthesized by $p$-aminobenzoic acid and $p$-aminosalicylic acid

acid and $p$-aminosalicylic acid reducing agent, which showed that the reducing agents could also act as a stabilizer.

The powder XRD pattern of the gold nanoparticles is shown in Fig. 9. The major diffraction peaks can be indexed as the face-centered cubic (fcc) phase based on the data from the JCPDS file (JCPDS no. 04-0784).

The diffraction peaks of gold nanoparticles that synthesized by $p$-aminobenzoic acid appeared at 38.3, $44.3,64.4$, and $77.6^{\circ}$, which could be assigned to (111), (200), (220), and (311) crystalline plane diffraction peaks of gold, respectively. For gold nanoparticle that synthesized by $p$-aminosalicylic acid the diffraction peaks appeared at $38.4,44.3,64.5$, and $77.5^{\circ}$, which could be assigned to (111), (200), (220), and (311) crystalline plane diffraction peaks of gold, respectively. The results show that the gold nanoparticles were completely formed using $p$-aminobenzoic acid and $p$-aminosalicylic acid as the reducing agent.

Overall, gold nanoparticles which synthesized with the reducing agent have a high stability. Each reducing agent used in this study has 2 or 3 active group; they are a carboxylic group, an amino group, and a hydroxyl group. These active groups would be deprotonated in basic $\mathrm{pH}$ system and formed a negative charge which enables the interaction between the reducing agents and the gold ion. The stability of nanoparticles was depended on the $\mathrm{pka}_{1}$ value of the reducing agent. The higher $\mathrm{pKa}_{1}$ value could increase the stability of gold-reducing agent complex and prevent the aggregation, therefore it could enhance the stability of gold nanoparticles. Besides the stability, the size of nanoparticles was depended on the reducing agent properties. A reducing agent with higher reduction ability would give smaller nanoparticle size because it could reduce more gold ions.

\section{- CONCLUSION}

Gold nanoparticles have been successfully synthesized from $\mathrm{HAuCl}_{4}$ by using $p$-aminobenzoic acid and $p$-aminosalicylic acid as a reducing agent and also stabilizer. The reaction took place on the basic $\mathrm{pH}$ condition, with optimum $\mathrm{pH}$ for $p$-aminobenzoic acid at $\mathrm{pH} 13$ and $p$-aminosalicylic acid at $\mathrm{pH} 11$. The maximum concentration of $\mathrm{HAuCl}_{4}$ was $140 \mathrm{ppm}$ and $100 \mathrm{ppm}$ for $p$-aminosalicylic acid and $p$-aminobenzoic acid, with maximum concentration for both the reducing agent, are $20 \mathrm{mM}$. The $p$-aminosalicylic acid reducing agent gave the smaller size gold nanoparticles $(7.45 \pm 1.5 \mathrm{~nm})$ and more stable gold nanoparticles than the $p$-aminobenzoic acid reducing agent (16.05 \pm 7.57 $\mathrm{nm})$. The extraordinary properties of synthesized gold nanoparticles have a strong impact in different science and technology fields. The range of applications for gold nanoparticles is growing rapidly and includes sensors, catalysis, therapeutic agent delivery, electronics, and photodynamic therapy.

\section{- ACKNOWLEDGMENTS}

The authors appreciate the Ministry of Research and Higher Education of Indonesian Republic which partly supported this research activity by providing a scholarship of Master Education Program Leading to Doctoral Degree for Excellent Graduates (PMDSU).

\section{- REFERENCES}

[1] Puddephat, R.J., 2008, Modern Supramolecular Gold Chemistry: Gold-Metal Interactions and Applications, (Eds.) Laguna, A., Wiley-VCH, Weinheim, John Wiley \& Sons, Inc.

[2] Chen, H., and Schluesener, H.J., 2008, Nanosilver: A nanoproduct in medical application, Toxicol. Lett., 176 (1), 1-12. 
[3] Regiel-Futyra, A., Kus-Liśkiewicz, M., Sebastian, V., Irusta, S., Arruebo, M., Stochel, G., and Kyzioł, A., 2015, Development of nontoxic chitosan-gold nano composites as efficient antibacterial materials, ACS Appl. Mater. Interfaces, 7 (2), 1087-1099.

[4] Aragay, G., Pino, F., and Merkoçi, A., 2012, Nano materials for sensing and destroying pesticides, Chem. Rev., 112 (10), 5317-5338.

[5] Corthey, G., Giovanetti, L.J., Ramallo-López, J.M., Zelaya, E., Rubert, A.A., Benitez, G.A., Requejo, F.G., Fonticelli, M.H., and Salvarezza, R.C., 2010, Synthesis and characterization of gold@gold(I)-thiomalate core@shell nanoparticles, ACS Nano, 4 (6), 34133421.

[6] Pal, T., Sau, T.K., and Jana, N.R., 1997, Reversible formation and dissolution of silver nanoparticles in aqueous surfactant media, Langmuir, 13 (6), 14811485.

[7] Goia, D.V., and Matijević, E., 1998, Preparation of monodispersed metal particles, New J. Chem., 22 (11), 1203-1215.

[8] Munro, C.H., Smith, W.E., Garner, M., Clarkson, J., and White, P.C., 2002, Characterization of the surface of a citrate-reduced colloid optimized for use as a substrate for surface-enhanced resonance Raman scattering, Langmuir, 11 (10), 3712-3720.

[9] Rodríguez-Sánchez, L., Blanco, M.C., and LópezQuintela, M.A., 2000, Electrochemical Synthesis of Silver Nanoparticles, J. Phys. Chem. B, 104 (41), 9683-9688.

[10] Zhu, J., Liu, S., Palchik, O., Koltypin, Y., and Gedanken, A., 2000, Shape-controlled synthesis of silver nanoparticles by pulse sonoelectrochemical methods, Langmuir, 16 (16), 6396-6399.

[11] Pastoriza-Santos, I., and Liz-Marzán, L.M., 2002, Formation of PVP-protected metal nanoparticles in DMF, Langmuir, 18 (7), 2888-2894.

[12] Barman, G., Maiti, G., and Laha, J.K., 2013, Biofabrication of gold nanoparticles using aqueous extract of red tomato and its use as a colorimetric sensor, Nanoscale Res. Lett., 8 (1), 181-190.

[13] Lu, Y.C., and Chou, K.S., 2008, A simple and effective route for the synthesis nano-silver colloidal dispersions, J. Chin. Inst. Chem. Eng., 39 (6), 673678.

[14] Leiva, A., Bonardd, S., Pino, M., Saldias, M., Kortaberria, G., and Radić, D., 2015, Improving the performance of chitosan in the synthesis and stabilization of gold nanoparticles, Eur. Polym. J., 68, 419-431.

[15] Bin Ahmad, M., Lim, J.J., Shameli, K., Ibrahim, N.A., and Tay, M.Y., 2011, Synthesis of silver nanoparticles in chitosan, gelatin and chitosan/gelatin bionanocomposites by a chemical reducing agent and their characterization, Molecules, 16 (9), 7237-7248.

[16] Haiss, W., Thanh, N.T.K., Aveyard, J., and Fernig, D.G., 2007, Determination of size and concentration of gold nanoparticles from UV-vis spectra, Anal. Chem., 79 (11), 4215-4221.

[17] Di Carlo, G., Curulli, A., Toro, R.G., Bianchini, C., De Caro, T., Padeletti, G., Zane, D., and Ingo, G.M., 2012, Green synthesis of gold-chitosan nano composites for caffeic acid sensing, Langmuir, 28 (12), 5471-5479.

[18] Aziz, M.A., Kim, J.P., and Oyama, M., 2014, Preparation of monodispersed carboxylatefunctionalized gold nanoparticles using pamoic acid as a reducing and capping reagent, Gold Bull., 47 (1-2), 127-132.

[19] Nadh, R.V., Sundar, B.S., and Radhakrishnamurti, P.S., 2001, Kinetics of oxidation of aniline, $p$ aminobenzoic acid, and $p$-nitroaniline by 2,6dichloroquinone-4-chloroimide, Russ. J. Phys. Chem., 75 (2), 229-233.

[20] Bala, R., Sharma, R.K., and Wangoo, N., 2016, Development of gold nanoparticles-based aptasensor for the colorimetric detection of organophosphorus pesticide phorate, Anal. Bioanal. Chem., 408 (1), 333-338.

[21] Nita, R., Trammell, S.A., Ellis, G.A., Moore, M.H., Soto, C.M., Leary, D.H., Fontana, J., Talebzadeh, S.F., and Knight, D.A., 2016, Kinetic analysis of the hydrolysis of methyl parathion using citratestabilized $10 \mathrm{~nm}$ gold nanoparticles, Chemosphere, 144, 1916-1919. 
[22] D’souza, S.L., Pati, R.K., and Kailasa, S.K., 2014, Ascorbic acid functionalized gold nanoparticles as a probe for colorimetric and visual read-out determination of dichlorvos in environmental samples, Anal. Methods, 6 (22), 9007-9014.
[23] Susanthy, D., Fadliah, Wahyuni, E.T., and Santosa, S.J., 2017, Synthesis of silver nanoparticles using $o$ hydroxybenzoic acid, $p$-hydroxybenzoic acid, and $o, p$-dihydroxybenzoic acids as reducing agents, Mater. Sci. Forum, 901, 26-31. 